PROBLEMS

OF MANAGEMENT

IN THE $21^{\text {st }}$ CENTURY

Volume 7, 2013

24

PROCEDURAL PARALLEL AND APPROACHES BETWEEN DECISIONS AND TRADE NEGOTIATIONS

\author{
Felicia Adriana Lupu \\ Oil \& Gas University of Ploiesti, Ploiești, Romania \\ E-mail: felilupu@yahoo.com
}

\begin{abstract}
In a conscious or less conscious way, in each moment of its existence, the organization negotiates. Any negotiation assumes the fact that the negotiator has to approach at least one decisional situation and has to make at least one decision.

Making decisions when negotiating, negotiators manifests their reasoning, proving the fact that they can approach decisional situations. Approaching the negotiation process by a string of decisional sequences, the entire theory regarding decision making may underline the process of negotiation, providing efficiency to the resources allocated within the process of negotiation and underlining the most equitable way and the most advantageous to follow for the team of negotiators.

On the basis of these ideas further questions can be put. Could any similarity be identified when comparing the decisional process to the result of a commercial negotiation? Do the negotiation's objectives determine the characteristics and particularities of the decisions to be made by each of the parts during the negotiation process?

Taking into account both the literature regarding the subject and the practical experience of the author in SMES's (Small and medium sized enterprise) management, using the analogy and deduction methods, this paper aims to identify procedural similarities between decisions and negotiations, reconsidering the role of the processes that have a managerial character.

Tracing such approaches may have multiple and major implications and is meant to underline the importance of the decisional process when it comes to negotiating.
\end{abstract}

Key words: decisional process, negotiations, competitive advantage, procedural approach.

\title{
Introduction
}

Any economic entity must negotiate as often as possible and learn the skills to negotiate properly (Cohen, 2006: 15). A constant development of the negotiating skills may bring the economic organization to situations of competitive advantage over the competition, competitive advantage which represents, overall, "the result of a strategy capable to reach and maintain a favorable position of the organization on the market" (Lupu, 2009a: 68). Depending on the depth and sizes of the negotiating skills acquired by the members of the organization, on the good foundation of the progress of the negotiating process and on the objectiveness with which the decisions are being addressed during the negotiation, an increasing number of the situations of competitive advantage may turn into lasting competitive advantage for the organization. At an objective analysis, one may note the fact that negotiation involves decision. The initiation of the negotiation involves the decision to start the process of negotiation. The progress of the negotiation assumes the decision to not stop the process of negotiation at a certain point. Ending the negotiation involves, equally, the decision to stop the negotiation in itself. Also, in a sequential approach of each of the stages or steps of a negotiation, we will observe the existence of an entire string of decisions. From this point of view, probably logical and legitimate, it is required 
to clarify this reasoning. Are negotiations a set of decisions? Are there common approaches for

The economic activity is a set of decisions. Consequentially, each economic activity in its specificity represents a set of decisions. Negotiations may be approached as simple acts of exchange or as complex and long lasting activities. In order to support the negotiating team or with the purpose of making the activity of the negotiators easier, a multitude of models of running negotiations have been developed. Approaching the process of negotiation by means of a string of decisional sequences, the entire theory regarding the foundation of the decisions may substantiate the negotiation process, streamlining the resources allocated during a negotiation process and indicating the most equitable way to follow by the team of negotiators. In order to make the resources of the organization more efficient, one could consider "the analysis of different categories of frequently used resources, their classification based on the content (human, material, financial) or based on the way of functional use within the organization (production, finances, staff, trade, research and computing). The elements that relate to the organizational culture are, generally, analyzed separately, being given more attention lately" (Lupu, 2009a: 75).

Given the considerations above, as well as the basic principles of the economic decisions, we estimate that it is appropriate to analyze the way in which these are adjustable to the specific activities followed by the team of negotiators during a negotiation, respectively the adaptability of the approaches and the basic principles of the process of decisions to the process of trade negotiations. Confirming the hypothesis may generate the enrichment of the assembly of theories regarding negotiations, techniques, tactics and negotiation strategies with the theories and decisional instruments existing in the specialized literature and used in practice.

\section{Methodology of Research}

In the current constantly changing economic environment, the decisional process becomes more and more complex. The characteristics of the internal and external environment have a major influence on the decisions adopted during the negotiation process. Making decisions within the trade negotiations, represents the central activity of the leader of the negotiation team, all the other activities unfolding in order to provide the making of the right decisions or, if the decision has already been adopted, in order to implement and monitor its efficiency within the process of trade negotiation. The multitude of methods which substantiate making decisions within the process of negotiations, in general, and of the process of trade negotiations, in particular, maximizes the value of the result of the negotiations.

In order to achieve the aim of this study, the specific and the common approaches of negotiations and decisions have been analized. By using the analogy and the deduction methods it has been tried to find a procedural similarity between decisions and negotiations, reconsidering the role of the processes that have a managerial character at the level of the economic activities.

\section{Results of Research}

\section{Specific Approaches of Negotiations and Decisions}

Any goods transfer involves simultaneously a transfer of the property right, a modification of the relation between the person and that's good, transformations which are based on a negotiation. "In any negotiating situation, there are always three elements which contribute proportionally with the quantity the negotiator owns of each of the three essential elements: information, time and power" (Cohen, 2006: 18). Negotiation represents an event closely related, to a certain extent, differing from case to case, to decisional sequences that must result in certain moments of time, information and power. 
PROBLEMS

OF MANAGEMENT

IN THE $21^{\text {st }}$ CENTURY Volume 7, 2013

26

"The essential difference between the various concepts and theories on negotiating is also related to the outstanding ways of accomplishing the processes of negotiation in themselves (...) Any negotiations are made in stages, with interruptions, periods of defining the points of view, for satisfying the partners" requests" (Lupu, 2008: 132). Negotiation is "a process that has as a purpose solving, clarifying, obtaining a deal between the two or more parties". (Boldur-Lăţescu, 1992: 75) The process of negotiation consists of discussions, procedures, correspondence, other methods of direct or indirect communication, between two or more partners in order to achieve an understanding on a matter. Equally the negotiation represents "an assembly of actions that approach and analyze problems that are of interest for the participants to the negotiation, with the purpose to find solutions of solving the addressed problems, solutions which are based on the loyal achieving of the interests of each of the parties participating directly or indirectly to the negotiation" (Boier, 1993: 12).

Negotiations are forms of collaborating "between the two or more parties in order to reach an understanding that can be recorded in an agreement or contract" (Hiltrop; Udall, 2007: 16), but can also be approached as "a complete process of planning, analyzing between two or more partners that are aiming for different results" (Day, 2006: 24). From this point of view, negotiation represents a process of planning, analyzing and talks, held between two or more partners in order to reach an understanding or trade transactions, economic cooperation or of any type.

One may claim about negotiations the fact that these represent using information and power in such a way to modify people's behaviour in a network of tension. From the point of view of the purpose of the negotiation, negotiation is the process by which two or more parties interact in order to achieve an acceptable position comparing to their divergent positions. "Negotiation is the art and science to find an agreement between two or more independent actors who are trying to maximize the results" (Popa, 2006: 107).

The decision was defined by various authors in approximately similar ways, as for example: "choosing a way or a line of action" (Simon, 1960: 8), "choosing an action strategy" (Fishburn, 1964: 76), the decision made as a result of the examination of a problem, situation, etc., the solution adopted from many other possible ones. The decision is the course of action chosen for achieving one or more objectives, under conditions of maximum efficiency (Nicolescu; Verboncu, 2007: 203). The decision represents, also, the result of processing some information and knowledge and belongs to a person or group of persons (deciders) who has the necessary authority and has the responsibility for the effective use of resources in certain given situations (Filip, 2002: 15).

The decision is, therefore, the action of application of resources, of establishing and achieving the firm's objectives. The decision requires an activity of preparation and elaboration involving a large number of persons from all the compartments of the organization.

From the point of view of the primary component of the decisional system, the decision represents an essential element of management, being found in all its functions. Ovidiu Nicolescu understands the decision of leadership as "the process of choosing a way of action in order to achieve some objectives, by whose application is influenced the activity of at least one person other than the decider" (Nicolescu, 1992: 109). In this case, the decisional situation (the situation in which a decision has to be made) implies one or more objectives to be reached, two or more alternatives of action that can provide achieving the proposed objectives, not knowing in anticipation the alternative which will optimize achieving the objectives and eventually, influencing the actions and, implicitly, of the behaviour of at least one person other than the decider, by applying the chosen variant.

Considering that: (1) the decision establishes the purposes and tasks of any economic system, and the subsequent functions of the management are determined by the purposes and tasks based on the adopted decision and because, (2) making a decision leads to using human, material and financial resources for the realization of some objectives accurately established, the decision represents the crucial moment of any process of leadership. Thus, the management 
decision implies at least two persons: the manager, the one who decides, and one or more persons, executors or average level managers, who participate at the application or realization

of the decision, decisoin that "should be made at the lowest level possible, which is accordant with the nature of the decision, and the closest possible to the place of action that the decision implies" (Drucker, 1973: 31).

\section{Common Approaches of Negotiations and Decisions}

The approaches regarding negotiation may be grouped in several categories. First of all, the negotiations are being approached normatively and descriptively. The normative approaches of the negotiations have learning as an objective, being based on the analysis of the negotiation process, and trying to find the rules to be applied in order to obtain an improvement in the performances of the parties engaged in this process. Here can be included: the "classical" approaches, that start from the observation and interpretation of the way in which the negotiators engaged in the talks act and are successful recipes, the approaches based on the theories and models of communication (the transactional analysis and the neurolinguistic programming), the method of the "objective negotiation" (Fisher; Ury, 1999: 18). The descriptive approaches of the negotiations, are monographic presentations of some important negotiations, which can serve as model in various fields or syntheses of observations regarding the progress of some complex negotiations. In other authors' opinion, "trade negotiation may be analyzed by means of two main approaches, respectively the theory of the games and the psycho-sociological approach" (Dupont, 2004: 35). The theory of the games highlights the existence of equitable solutions for the actors of the negotiations, solutions that allow them to maximize their profit (e.g. Nash's equilibrium). This theory involves a series of unrealistic assumptions (e.g. actors' reasoning, situations of bilateral monopoly or oligopoly, absence of behaviour differences, knowing the utilities of the other part (Popa, 2006: 122).

A first observation of the procedural similarities between decisions and negotiations is encountered in the identical approach of the process of the decisions with the one of the negotiation. From this point of view, one can observe the fact that decisions are also approached both descriptively and normatively. The descriptive approaches of the decisions aim to explain the real behaviour within the decisional process. The model of descriptive approach is a behaviour model which takes into account the imperfections in the held knowledge or in the behaviour of the ones involved in the decisional process. The deciders do not know entirely the available alternatives and there is no unique or well defined objective. One can only conduct a limited research of the environment in order to discover a few satisfactory alternatives and to finally make a satisfactory decision. Reasoning is limited and incomplete, which means that the decisional process is rational, but within the limit of the imperfections of the information and of the ability of the decider to perceive alternatives and results. An important consequence of this type of behaviour is the one that, in order to make the decision, subjectivity and judgement are being used as more than explicit rules of decision. An information system for assisting the management must offer the deciders basic information and means to rather explore the alternatives than rules and mechanical procedures of decision. Often, taking into account the pressure the managers are being subject to and every day problems, the deciders are choosing a good enough alternative of a limited series of possible alternatives. In practice, the deciders simplify the involved factors and, due to practical difficulties, are prepared to accept satisfactory solutions rather than waste time and resources in the attempt to find the theoretical optimum.

The normative approaches of the decisions present the methods and the way in which the organization management should proceed in order to substantiate, adopt and apply effective and efficient decisions (Nicolescu; Verboncu, 2007: 211). The normative approach model of the decisions implies the fact that all the factors involved in the respective decision are known and that it is adopted a rational mechanical approach of the decisional process. In practice all the cri- 
Felicia Adriana LUPU. Procedural Parallel and Approaches between Decisions and Trade Negotiations

PROBLEMS

OF MANAGEMENT

IN THE $21^{\text {st }}$ CENTURY Volume 7, 2013

28

teria of the model are hard to be fulfilled simultaneously. However, the prescriptive models are very often used, being applied especially at the operational and tactical level where the factors are more clearly specified and there is less uncertainty, the support systems for the management being able to assist the decisional process. In many cases, the results offered by such a model are treated as one of the pieces of information to be taken into consideration by the manager during the decision making process or during the process of its adjustment. The normative models are models which automatically select the best option (ex. linear programming, cost-volumeprofit analysis, statistical decisional theory, analysis techniques of the investment). Most of the times, decisions are not isolated, being part of a sum of decisional sequences.

Stages of the negotiating process. The rigorous delimitation of the negotiating concept, in theory and practice of trade negotiations, leads to the identification based on the synthesis of the unfolding of the transaction action, of three successive negotiation stages, respectively pre-negotiations, negotiations itself and post-negotiation.

Pre-negotiation, as a first unfolding stage of any negotiation, begins with the first discussion or communication, discussion during which the future transaction partners declare their interest and ends the moment when the parties' interest is officially declared. This stage includes discussion, exchanging opinions, calls, smaller or larger reconsiderations, possible compromises in terms of preparing a mutually convenient understanding or at least reciprocally acceptable.

During the pre-negotiation stage the parties are reciprocally studying their potential, analyze their interests regarding the development of the activity and have discussion which prepare the setting for the negotiation itself. The negotiation itself begins the moment the interest of the parties is being declared for discussing the object to be negotiated, following closely, by each of the party involved, a well defined purpose and at the same time, achieving or satisfying the common interest and the mutual advantage of the parties. In practice it is difficult to limit the negotiation itself, as it depends on time and setting of the trade negotiations held, as well as on the type of object of negotiation. In any approach, one may consider the fact that negotiation it begins when the parties sit at the negotiation table, knowing what their interests are towards the object of negotiation.

Post-negotiation begins when the document for completing the negotiation is signed by the parties and consists of achieving the assumed obligations. "An important component of this stage is the appreciation of the results, the efficiency of the operation, this being a possible starting point for the future operations with the same partner. In this case, the contact between the partners becomes permanent" (Lupu, 2007: 384).

Apart from the negotiations themselves, which assume the meeting of some authorized representatives of the parties, having an agenda and a procedure jointly established in order to achieve an objective under the form of a written agreement, there is between the parties a permanent activity of silent accommodation and harmonisation of the attitudes, called proto negotiation. "Proto negotiations consist in an unilateral act that is considered as signal, by the interested parties, is deciphered, interpreted and commented by the party that feels targeted" (Malița, 1972: 142). In other words, "when we proto negotiate, we are negotiating with a partner we do not see and who does not see us, probably the same feeling we have in a discussion by ourselves in an empty and dark room. In the wider context of a negotiation, any form of indirect communication used for supporting completing an agreement, regardless of the form of the agreement, transposes in the proto negotiation" (Lupu, 2009b: 208).

The stages of the decisional process. The decision making process consists of a series of steps that the managers follow, either formally, or based on intuition, in choosing the alternative considered optimum. As a general view, making the decision process is formed of three main stages: finding opportunities to make decisions, discovering the possible courses of action and choosing the decision of the possible identified courses (Simon, 1960: 73). Within the decisional process, adaptable to the organizations of Romania, one needs to follow several stages: identifying the problem, generating alternative solutions, selecting the most beneficial 
alternative, implementing the chosen alternative and obtaining a feedback in order to evaluate the efficiency of the decision (the evaluation of the decision). Taking the five classical stages may lead, in some researchers' opinion, to detailing some of the stages of the decisional process, to the models of phasing with an incredibly high number of stages. Thus, the decisional process may assume carrying out the following stages: "identifying the problem, isolating the factors which occur as interacting in order to produce the observed symptoms, tracing some loops of information, identifying cause-effect reactions that link decisions to actions, building a mathematical model of the decision strategies and of the information sources and interactions between the system's components, generating in time a behaviour of the system, comparing results to all the relevant knowledge on the system, reviewing the model until it becomes acceptable as representation of the current system, redesigning, within the model, of the organizational relations and of the strategies that may be modified in the current system, in order to determine the changes that improve the system's behaviour, the modification of the real system in terms of the model's experimentation showing that an improvement of the perfomances may be achieved" (Forrester, 1981: 27).

\section{Discussion}

The decisional process consists of the assembly of phases by means of which it is prepared, adopted, applied and evaluated the managerial decision (Nicolescu; Verboncu, 2007: 205). The decisional process as a whole, highlights the categories of variables which influence the decisional process: variables which affect the objectives of the organization, variables which affect the expectations of the organization and variables which affect the choices of the organization (Cyert; March, 1964: 145).

Equally the process of negotiation implies the existence of the negotiation environment with all the variables involved, the object of negotiation, the areas of interest, the convergent objectives and the divergent objectives which is constituted through the reports established by the interested parties with the negotiation environment and with the object of negotiation (Deac, 2002: 78). Both processes are influenced by the environment that characterizes the organization, the aimed procedural objectives generating the normative character of the purpose of the process. The object of negotiation is the central element of the structure of the process that triggers the decisional conflict between the parties engaged in the negotiation, representing at the same time the object of their interests and desires. This element will constitute the final goal for which the negotiation strategies and techniques are being elaborated, which will substantiate the decision that will finalize the negotiation process and the entire process will take place around it. The place the object of the negotiation may occupy in the configuration of the respective field, determines to a great extent the characteristics and features of the decision that each of the interested parties will adopt in order to claim its object of negotiation. Decisional conflicts that occur inside the team of negotiation may be the result of designing their own objectives, by the members of the engaged team, on the object of negotiation.

A special emphasis is given to the role of the people envolved in this situation, specifying the fact that, the absence of some appropriate economic results, by lack of staff adhesion to the accomplishment of the assigned objectives, is caused by deficient motivation and participation to the unfolding of the strategic, tactical and current decisional processes.

From the point of view of the objectives of both teams engaged in the negotiation, the objectives that the interested parties propose and follow may be convergent or divergent. Convergence and divergence in objectives is analyzed by taking into account their position in relation to the object of negotiation. Convergence of the objectives recommends the necessity of ending the conflict through negotiation. The objectives of the parties that are found to be in divergence, allow unfolding of the process by making concessions in order to reach some decisions of secondary importance to allow resuming the process of negotiation with a further stage. In the attempt to create a complete system of sequences of decisions to substantiate the 
Felicia Adriana LUPU. Procedural Parallel and Approaches between Decisions and Trade Negotiations

PROBLEMS

OF MANAGEMENT

IN THE $21^{\text {st }}$ CENTURY

Volume 7, 2013

30

process of negotiations different models of simulation of the negotiations and bargaining games have been identified or created. Conditioning the reaching of the proposed objective with the decision to initiate negotiation represents the essential philosophy of the decision to finalize the negotiation, the effective goal of the unfolding of the negotiation.

Any conscious economic action is based on a decision to achieve a goal or objective. In this context, the object of negotiation represents the commitment assumed by the one who authorizes the team of negotiators, the one who has the initiative of the negotiation decision, regarding the future activity of the organization. Also, accomplishing the object of negotiation, expresses the existential reasoning of the respective negotiation, the purpose for which the initiation decision of the negotiation is justified. Equally, the decision in negotiation may mean the trenchant element of achieving the objectives of the negotiation. The sequencing of the decision throughout a negotiation, their coherent identification throughout the logical model of simulating the negotiations, generate the coherence of the negotiation as a whole.

The procedural similarity between decisions and negotiations is strengthened by the fact that both processes are the result of the option from many possible and probable variants that generate the satisfaction, from a certain point of view, of the organization and its members. The decisional process represents the entire evolution of the events that will be finalized by choosing one of the possible variants, variant which under the given circumstances is the most advantageous for the organization. The manager of the organization goes through a series of options, phases, stages of the decisional process until he/she reaches the identification of the most advantageous option. During the process of negotiation, the agreement options are known, having been identified even before starting the negotiation. But these adjustments cannot overcome the spread of the range of agreement options assumed within the negotiation mandate. In the situation in which the adjustments overcome the principal's limits, the negotiation will obviously be reconfigured after certain pauses. Therefore, the process of negotiation represents a process of choosing among the several possible and probable variants that satisfy the organization and its members. The difference, in this situation, being given by the fact that the choice is adjustable in relation to the options of the negotiating partner.

The decision is an activity of preparation and elaboration involving a large number of specialists from all the compartments of the organization. By virtue of making the decision an amount of variants and options drawn from the decisional process is simulated. The manager of the organization or the managerial team will eventually choose the decision option that best satisfies the interests of the organization at that moment. Preparing and elaborating the variants belong to the team and choosing the decision option, belongs to the manager of the organization.

In the case of the trade negotiations, the situation is relatively similar. Preparing the negotiation is attended by a team formed of specialists in several fields related to the negotiation that is about to take place. Following the conjoint or on sections activities of the entire team or its members, the files of the negotiation, the circumstances in which the negotiation will take place, the variants of the unfolding of the negotiation, etc., are being prepared. All these efforts of preparing the negotiation are made in order to achieve the proposed objective. Most of the times the objective proposed during the trade negotiations is given by concluding an agreement. This agreement is configured following the options of the principal of negotiation, not being able to overcome the elements set out in the principal of negotiation. The negotiation is prepared by a team of specialists, choosing the agreement variant that is to be concluded, is already made and belongs to the manager of the organization.

There are also situations in which for the unfolding of a negotiation a team of external negotiators is called up. At the right moment, they will have to make the choice between the agreement option that will seal the completion of the negotiation. At a first view of the script, one would estimate the fact that making an option over the agreement is outsourced. But in this position the choice belongs also to the negotiator. The external team of negotiators has a mandate and will have to comply to it. The negotiators prepare and carry out the negotiation, 
but the choice belongs also to the manager of the organization. The reasoning may be extended over any moment of the negotiation. The approach of the negotiation is a normative one. The negotiation can be stopped, for example, only in certain situations that are stipulated with the knowledge and approval of the principal of the negotiation.

The same situation may be encountered in the decisional process. There may be external specialists who prepare the possible options for decision. Choosing between the possible alternatives will be made also by the manager of the organization. In the situation in which reality is not as such, one may estimate that there are malfunctions in the system.

The examples of procedural similarity and approach existing between decisions and negotiations may continue. The result will be the same. We will still insist on offering an example of a case of relatively innovative approach. Besides the negotiations themselves, which imply the meeting of some authorized representatives of the parties, having an agenda and a procedure jointly established in order to achieve an objective under the form of a written agreement, some permanent activity of silent accommodation and harmonization of the attitudes exists between the parties, activity which can be called proto negotiation, consisting "in an unilateral action that is taken as a signal, by the interested parties, it is decoded, interpreted and commented by the party that feels targeted" (Lupu, 2009c: 334).

Analyzing the process of unfolding of a decision, we can find the existence of a permanent state of silent accommodation and harmonization of the attitudes. The manager hesitates in making the choice, still analyzes, there is the possibility of abandoning making a decision, or we may even speak of a partial decision. The situation does not represent a completion of the decisional process but it can be an adjustment of the state of the party involved in the process which can stand for a trenchant and conscious decision. The results may be similar to the ones in the situation in which the decisional process will be finalized. Because it is not a decisional situation, but has the same characteristics and the result may be the same, shall we name this state proto decisions? The correct thing to do is probably to make a record of the procedural resemblance and approach between decisions and negotiations, and the result of this similarity to be, as much as possible, used in the practical space, or in any other circumstances, to substantiate the decision the best way in the trade negotiations or of any other type.

\section{Conclusions}

The procedural character of these two activities is extremely similar. This similarity observed between the process of negotiating and the one of decision making, based on the relatively similar approaches and phases, generate coherence and simplicity during the process of trade negotiations. Equally, such an approach comes to underline the potential of extending the instruments of decisional nature within the methods and techniques that substantiate the activity of the team of negotiators. Pointing out such approaches and principles of the applicable decisions throughout the process of trade negotiations is meant to underline the importance of the decisional process during the negotiations, in particular, and at the level of the whole economic activity, in general.

The current approach initiates a reconsideration of the role of the processes that have a managerial character at the level of the economic activities. Also, the main purpose of initiating such an approach is to thus broaden interdisciplinarity and eliminate barriers between the exhaustive and theleological approaches of the processes at the level of the economic activities.

\section{References}

Boldur-Lăţescu, Gh. (1992). Decisional logic and management systems. Bucharest: Academy Publishing.

Boier, R. (1993). Consumer behavior. Iași: Graphix Publishing.

Cohen, H. (2006). Art of negotiating. Bucharest: Humanitas Publishing. 
Felicia Adriana LUPU. Procedural Parallel and Approaches between Decisions and Trade Negotiations

PROBLEMS

OF MANAGEMENT

IN THE $21^{\text {st }}$ CENTURY Volume 7, 2013

Cyert, R. M., \& March, J. G. (1964). A Behavioral Theory of the firm. The American Economic Review, 1 (54), 144-148.

Day, M. (2006). Negotiations commercials. Paris: Hachette.

Deac, I. (2002). Introduction to negotiation theory. Iași: Paideia.

Dupont, C. (2004). Le negotiation. Conduite, Theorie, application (5th Ed.). Paris: Dalloz.

Drucker, P. (1973). Management. New York: Harper\& Row.

Filip, F. Ghe. (2002). Computer aided decision, decisions, decisions makers, methods and basic tools. Bucharest: Expert Publishing.

Fishburn, P. C. (1964). Decision and Value Theory. New York: John Wiley and Sons.

Fisher, R., \& Ury, W. (1999). Getting to Yes (2nd Ed.). London: Penguin Book.

Forrester, J. W. (1981). Industrial dynamics. Bucharest: Technical Publishing.

Hiltrop, J. M., \& Udall, Sh. (2007). The art of negotiations. Bucharest: Teora.

Lupu, A. G. (2007). The efficiency of protonegociations in commercial negotiations process. In: I. Vasilescu, F. Luban (Eds.), Investment and Economic Recovery (pp. 382-386), Bucharest: ASE.

Lupu, A. G. (2008, April). Issue of protonegociations in negotiation process. In: C. Teodorescu (Chair), International Scientific Session - Strategies XXI, Bucharest, Romania.

Lupu, A. G. (2009a). Managerial analyses models in knowledge society. Economy. Seria Management, 12 (1 special), 68-79.

Lupu, A. G. (2009b). Innovation in negotiations. Management and Economic Engineering Review, 2 (32),

203-214

Lupu, A. G. (2009c). Protonegotiations - sales forecast and competitive environment analysis method. Annals of Faculty of Economics, 4 (1), 334-338. Retrieved from http://steconomice.uoradea.ro/ anale/volume/2009/v4-management-and-marketing/56.pdf

Malița, M. (1972). Theory and practice of negotiations. Bucharest: Politica.

Nicolescu, O. (1992). Management. Bucharest: Didactic and pedagogical publishing.

Nicolescu, O., \& Verboncu, I. (2007). Organisation's management. Bucharest: Economic Publishing.

Popa, I. (2006). International trade negotiations. Bucharest: Economic Publishing.

Simon, H. A. (1960). The New Science of Management Decision. New York: Harper and Row.

Advised by Iwona Gorzeń-Mitka, Czestochowa University of Technology, Poland

Received: April 21, 2013

Accepted: June 17, 2013

Felicia Adriana Lupu

Ph.D., Associate Professor, Oil \& Gas University of Ploiesti, Grigore Alexandrescu Street, No1, 100567 Ploiești, Romania.

E-mail: felilupu@yahoo.com 